\title{
The effect of an active implementation of a disease management programme for chronic obstructive pulmonary disease on healthcare utilization - a cluster-randomised controlled trial
}

\author{
Margrethe Smidth ${ }^{1,2^{*}}$, Morten Bondo Christensen ${ }^{1}$, Morten Fenger-Grøn ${ }^{1}$, Frede Olesen ${ }^{1}$ and Peter Vedsted ${ }^{1}$
}

\begin{abstract}
Background: The growing population living with chronic conditions calls for efficient healthcare-planning and effective care. Implementing disease-management-programmes is one option for responding to this demand. Knowledge is scarce about the effect of implementation processes and their effect on patients; only few studies have reported the effectiveness of disease-management-programmes targeting patients with chronic obstructive pulmonary disease (COPD). The objective of this paper was to determine the effect on healthcare-utilization of an active implementation model for a disease-management-programme for patients with one of the major multimorbidity diseases, COPD.
\end{abstract}

Methods: The standard implementation of a new disease-management-programme for COPD was ongoing during the study-period from November 2008 to November 2010 in the Central Denmark Region. We wanted to test a strategy using Breakthrough Series, academic detailing and lists of patients with COPD. It targeted GPs and three hospitals serving approx. 60,000 inhabitants aged 35 or older and included interventions directed at professionals, organisations and patients. The study was a non-blinded block- and cluster-randomised controlled trial with GP-practices as the unit of randomisation. In Ringkoebing-Skjern Municipality, Denmark, 16 GP-practices involving 38 GPs were randomised to either the intervention-group or the control-group. A comparable neighbouring municipality acted as an external-control-group which included nine GP-practices with 25 GPs. An algorithm based on health-registry-data on lung-related contacts to the healthcare-system identified 2,736 patients who were alive at the end of the study-period. The population included in this study counted 1,372 (69.2\%) patients who responded to the baseline questionnaire and confirmed their COPD diagnosis; 458 (33.4\%) patients were from the intervention-group, 376 (27.4\%) from the control-group and 538(39.2\%) from the external-control-group. The primary outcome was adherence to the disease-management-programme measured at patient-level by use of specific services from general practice. Secondary outcomes were use of out-of-hours-services, outpatient-clinic, and emergency-department and hospital-admissions.

(Continued on next page)

\footnotetext{
*Correspondence: m.smidth@alm.au.dk

${ }^{1}$ The Research Unit for General Practice, Aarhus University, Aarhus, Denmark

${ }^{2}$ The Section for General Medical Practice, Aarhus University, Aarhus, Denmark
} 


\begin{abstract}
(Continued from previous page)
Results: The intervention practices provided more planned preventive consultations, additional preventive consultations and spirometries than non-intervention practices. A comparison of the development in the intervention practices with the development in the control-practices showed that the intervention resulted in more planned preventive-consultations, fewer conventional consultations and fewer patients admitted without a lungrelated-diagnosis.
\end{abstract}

Conclusions: Use of the active implementation model for the disease-management-programme for COPD changed the healthcare utilization in accordance with the programme.

Trial registration: Clinicaltrials.gov identifier: NCT01228708.

Keywords: Implementation, Disease management, Healthcare utilization, COPD, Chronic Care Model, RCT

\section{Background}

The number of people living with chronic conditions is growing as a result of lifestyle, increased life-expectancy, improved treatment options and growing diagnostic activity [1]. This situation demands efficient healthcare planning and effective care. Danish healthcare is tax-financed and citizens therefore enjoy free use of healthcare at the point of care. The nearly 3,600 general practitioners (GPs) are gatekeepers for access to most of the healthcare system. The GPs operate as independent contractors under a system of five regions and are remunerated on a combination of fee-for-service and capitation basis (75/25). Each of the 98 Danish municipalities is responsible for providing rehabilitation services and preventive care for their citizens. The five Danish regions are responsible for services from hospitals and general practice.

The Danish Health and Medicines Authority estimates that $80 \%$ of healthcare costs are spent on people living with one or more chronic conditions [2]. It has been argued that healthcare may be improved and public spending reduced by implementation of an efficient strategy that ensures seamless care for patients through the concerted effort of general practices (GP practices), hospitals and the municipalities [3-6]. Only few studies have investigated the economy and the healthcare utilization of the integrated care programmes [7]. Wennberg has dismissed the idea that "more is better" within healthcare provision [8], but argues that the care provided rather needs to be targeted and focused.

Chronic obstructive pulmonary disease (COPD) is an important non-communicable disease. It ranks as the fifth leading cause of death globally [9], and Denmark has the highest COPD incidence rate among the European countries [10]. COPD is an underdiagnosed, irreversible and potentially life-threatening condition where secondary prevention, treatment and rehabilitation with systematic follow-up may help control the symptoms, increase the patient's quality of life and delay disease progression [11]. Newly published results indicate that $14.3 \%$ of people aged 35 years and older have COPD [12]; yet, only $28 \%$ of these people have been diagnosed [13].

In 2008, the Central Denmark Region implemented a new disease management programme for COPD inspired by the Chronic Care Model (CCM) [14]. However, implementation can be challenging, and knowledge about the effects of the implementation processes and their possible effect on patients remains scarce $[15,16]$. Lugtenberg et al. argue that active leadership is required to implement change [17], and Greenhalgh states that targeted change must be simple and adjustable to each locality [18]. Grol et al. show that implementation in healthcare needs to involve evidence-based information, few and precise recommendations and practical advice to secure implementation in clinical practice [19]. Several randomised studies have reported that implementation of disease management programmes for chronic conditions could reduce hospital admissions, out-of-hours services and emergency department attendance [20-24]. One cohort study found that implementation of a disease management programme reduced readmissions to hospital [25], but only few studies have examined the effectiveness of disease management programmes targeting patients with COPD [26,27].

The aims were, first, to investigate the impact of the previously developed active implementation model for a disease management programme for COPD as measured by specific indicators to determine to which degree the GPs follow the recommendations; and, second, to determine the extent of healthcare utilization in primary and secondary care for patients with COPD. The programme was developed on the basis of the CCM [28].

\section{Methods}

\section{Study design}

The study was a block- and cluster-randomised controlled trial with intervention and control groups and an additional external control group. The intervention group consisted of patients from half of the general practices in the Ringkoebing-Skjern Municipality in Denmark. Patients from the other half of the practices formed the control 
group. Patients in a comparable neighbouring municipality (Ikast-Brande) formed the external control group which was established to control for a spillover effect of the intervention conducted within the municipality $[29,30]$. To identify patients highly suspected for having COPD, we used a validated COPD algorithm [31].

\section{Setting}

The study period spanned from November 2008 to December 2010. The study was conducted in the western part of the Central Denmark Region, where secondary care is provided by three regional hospitals in Ringkoebing, Herning and Holstebro. Two comparable municipalities in the region provided the setting for the study.

All citizens living in Denmark are registered with a personal identification number, the CPR number. This allows unique linkage between all the national registries at the level of the individual [32]. The GPs are eligible for reimbursement of the services they provide and they must submit electronic reimbursement claims to the Danish National Health Insurance Service Registry (DNHISR). Information about all Danish citizens' use of general practice services, including out-of-hours services, can be obtained from the DNHISR [33,34]. All hospitals must report outpatient visits, contacts to the emergency department, hospital admissions and discharges to the regional Patient Administrative System (PAS) using International Classification of Diseases (ICD-10) codes.

During the study period, the Ringkoebing-Skjern $\mathrm{Mu}$ nicipality had approximately 58,000 inhabitants of whom 35,000 were aged 35 or above. The municipality had 38 GPs organised into 15 practices. The neighbouring municipality (Ikast-Brande) had close to 40,000 inhabitants of whom 24,000 were aged 35 or above, and 25 GPs organised into ten practices. In all practices, staff (i.e. nurses, laboratory technicians or secretaries) employed by the GPs conducted either the whole or a part of the consultations on their own.

\section{Intervention}

The intervention practices undertook an active, structured implementation of a disease management programme for COPD. The intervention is depicted in the Additional file 1 ; we have described the development of the intervention in detail elsewhere [35]. The intervention comprised components from the main areas of the CCM - Policies and Resources, Self-Management Support, Delivery System Design, Organisation of Healthcare and Clinical Information System [36]. To stimulate the process, we asked a local, esteemed opinion leader to introduce and support the intervention [37] both to GPs and to the municipality.

The intervention practices were invited to participate in four two-and-a-half-hour sessions. The Breakthrough
Series [38,39] was used as a framework for the implementation of planned and targeted changes. All meetings were chaired by experts and experienced facilitators, who were all clinically educated and experienced in aiding change in practice. One facilitator (MS) visited each practice to explore and/or address challenges encountered in pursuing their goals.

We negotiated our implementation strategy with the municipality, which took active ownership by increasing the number of free COPD courses and smoking cessation courses. The region agreed on providing a special reimbursement to GPs for joint home visits together with the community nurse to newly discharged COPD patients [40].

Targeted self-management support for patients to cope with exacerbations of the disease was an integral part of our strategy, and we developed an action card with advice to patients on management of sputum and exacerbations. The action card was based on the research by Robert Stockley $[41,42]$.

To provide family, friends and the patients themselves with more knowledge to improve their ability to cope with their disease, we designed a web site with information about COPD including contact details to the municipality, patient support groups and the involved GPs.

The standard implementation of the disease management programme from the Central Denmark Region went ahead and thus also covered all the groups in our study.

\section{Randomisation and sample size}

\section{Randomisation and allocation concealment}

All GP practices were included in the study. An independent researcher drew slips that were matched to an electronic record of all GP practices in the Ringkoebing-Skjern Municipality. The practices were block-randomised into three blocks. The first block consisted of solo-practices; three practices were drawn to the intervention group and two to the control group. The second block consisted of practices with two GPs; three practices were drawn to the intervention group and two to the control group. The third block consisted of practices with three or more GPs; three practices were allocated to the intervention group and three to the control group. In the external control group, there were two solo-practices, three practices with two GPs and four with three or more GPs. One practice with three GPs was allocated to the intervention group as one of the GPs was partly involved in the overall planning of the study. Out of the nine invited intervention practices, seven accepted the invitation to participate. In accordance with the intention-to-treat principle, the two practices that declined the invitation to participate remained in the intervention group. In total, 21 GPs were randomised to the intervention group and 17 to the control group; the external control 
group consisted of 25 GPs. The characteristics of the GPs can be found in Table 1.

The allocation of both GPs and patients to the intervention and the control group was open and known to the GPs and also to the researchers as it was not possible to hide the allocation to the researchers who also delivered the intervention to the GP practices.

Patients identified by the COPD algorithm from all three groups were sent a baseline questionnaire and patients from the intervention group were also sent a flyer. Furthermore, a poster was displayed in the practice premises informing the patients that this practice was an intervention practice. Only people coming into the premises could see it. In Denmark, every citizen is listed with a particular GP practice and can only use the services from this practice, and patients rarely want to change practice. It is most unlikely that a person would change practice because of a poster.

\section{Sample size}

To detect a change from 50 to $60 \%$ in the proportion of patients having a yearly follow-up consultation for their chronic disease (with $80 \%$ power at the 0.05 level of significance), a total of 816 patients with 408 in each group would have to be included in the study. With a design effect of 1.6, we would need 1,306 patients for the study.

\section{The COPD algorithm}

The COPD algorithm was validated in a previous study which suggested that it could be used as a tool to identify patients with obstructive lung disease, primarily COPD [31]. The search algorithm was based on administrative data on hospitalisation, redeemed prescriptions for lung-related drugs and spirometries performed in the GP practice; thus, the patients had already been in contact with the healthcare system for a lung-related issue. A prerequisite for identification was that the patient should be 35 years old or older and be registered with a
GP practice in the patient's residing municipality. The patients were identified either because they had been hospitalised during the past five years with a lungrelated diagnosis, had redeemed prescriptions on lung medication at least twice during the past year or had had their lung function tested at their GP on two different occasions during the past year.

\section{Participants}

The patient population comprised 3,021 patients from the two municipalities who were identified by the COPD algorithm [31]. Among these patients, 1,819 were from the Ringkoebing-Skjern Municipality and 1,202 were from the neighbouring municipality. Of the identified patients, 2,895 had a GP in the municipality of their residence. At follow-up, 159 had died or sought research protection. All patients received a questionnaire at baseline. The study population consisted of responders who confirmed their COPD diagnosis, called the CD population. Patients who died during the intervention period were excluded (Figure 1).

All patients followed their GPs' allocation to intervention, control group or external control group and would only drop out of the study if their GP did so or if they moved out of the municipality. No GP dropped out of the study.

\section{Data}

The primary outcome was adherence to the disease management programme in the GP practices. Adherence was measured at the patient level in terms of use of the specific services of planned and additional preventive consultations, and the number of spirometries. The GP practices report each of these services to the region to be reimbursed.

The secondary outcome was use of out-of-hours services, outpatient clinic and emergency department attendances as well as hospital admissions. For admissions to

Table 1 Baseline characteristics for GPs as of 2008

\begin{tabular}{|c|c|c|c|c|}
\hline & Intervention & Control & Ext. control & Total \\
\hline N (\%) & $21(33.3)$ & $17(27.0)$ & $25(39.7)$ & $63(100)$ \\
\hline Male (\%) & $14(66.7)$ & $13(76.5)$ & $13(52.0)$ & $40(63.5)$ \\
\hline Mean age in years (min-max)* & $51.6(36-62)$ & $49.2(37-65)$ & $51.6(32-63)$ & $50.9(32-65)$ \\
\hline Mean number of patients per GP (SD) * & $1579(210)$ & $1290(457)$ & $1108(295)$ & $1296(386)$ \\
\hline No COPD CME ${ }^{* *}$ Attendance (\%) & $4(21.1)$ & $5(38.5)$ & \# & \# \\
\hline Did not routinely perform spirometry for smokers with symptoms (\%) & $10(50.0)$ & $4(30.8)$ & \# & \# \\
\hline Did not routinely stratify patients with COPD (\%) & $9(45.0)$ & $6(46.2)$ & \# & \# \\
\hline Did not routinely note the MRC score in the patient file (\%) & $15(75.0)$ & $10(76.1)$ & \# & \# \\
\hline Did not routinely provide prescription for antibiotics (\%) & $18(90.0)$ & $11(84.6)$ & \# & \# \\
\hline
\end{tabular}

${ }^{*} p<0.001$ Chi square test or linear regression model applied.

**CME COPD-related continued education.

\#No questionnaire data from external control group. 

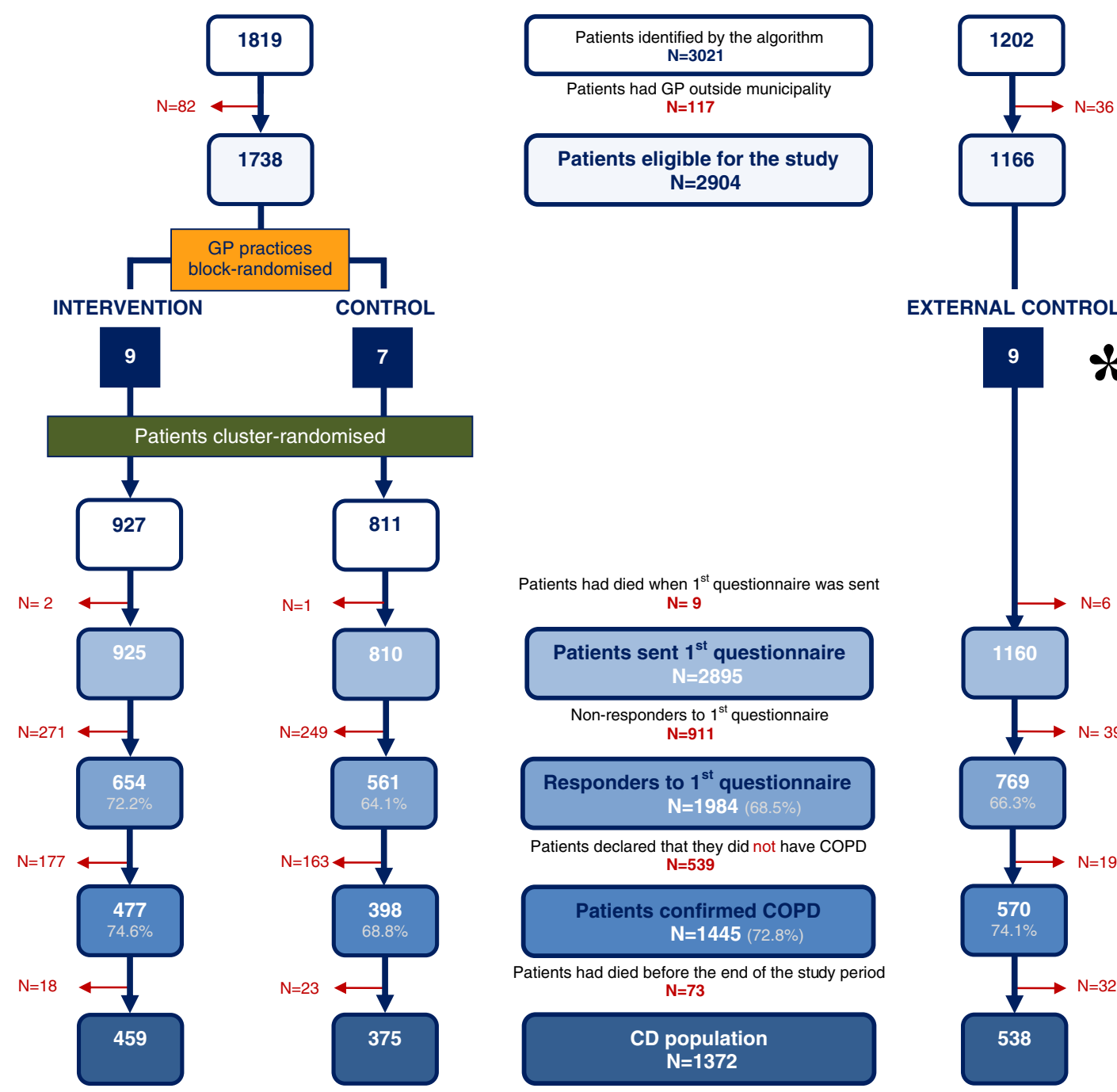

EXTERNAL CONTROL

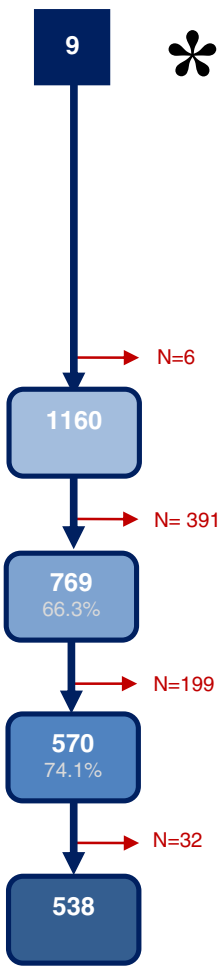

\section{* Definition of sub-group for Sensitivity analysis:}

$\left.9 \begin{array}{c|c}\text { GP practices } \\ \text { block-randomised }\end{array}\right] \mathbf{7}$ INTERVENTION

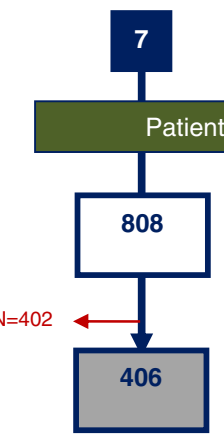

CONTROL

Two GP practices were removed from the analysis as they declined to participate in the intervention $\mathrm{N}=119$
9

EXTERNAL CONTROL

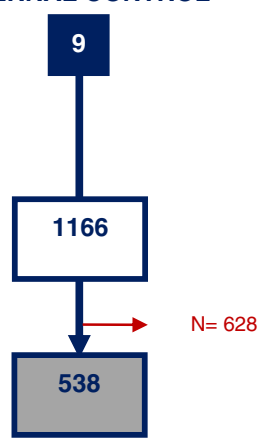

Figure 1 Flowchart for cluster-randomised study and patient flow in this and in the extra added group. Patient inclusion and exclusion presented in numbers with percentage distribution indicated below numbers. 
hospitals, we defined a readmission as an acute admission concerning COPD within 30 days of the last admission.

\section{Register data}

We collected data from the DNHISR [33,34] and the regional PAS for all 2,736 patients identified by the COPD algorithm from 1 November 2008 to 31 October 2010 (12 months before and 12 months after the start of the intervention).

\section{Questionnaire data}

A baseline questionnaire was sent to all identified patients. The questionnaire included validated tools to assess the patients' respiratory state and mental health; their experience of their health, care and practice (Medical Research Council's dyspnoea scale [43], the Major Depression Inventory (MDI) [44], their self-reported health (EQ-5D) [45], the Patient Assessment of Chronic Illness Care (PACIC) [46] and the Danish Patients Evaluate Practice (DanPEP) [47]). The questionnaire also contained questions regarding use of medication, support and socio-economic issues developed on the basis of literature, clinical experience and interviews with patients and healthcare professionals. Patients who confirmed their diagnosis were sent a questionnaire at follow-up. The results from the PACIC have been reported elsewhere [48].

\section{Analyses}

The effect of the active implementation was analysed by comparing the changes in the intervention group with the changes in both the control group and the external control group. For each of the outcomes, we calculated yearly rates and rate ratios (RRs) between the year before and the year after the intervention. To determine the differences between the groups, the corresponding pairwise RRs between the groups were calculated. To facilitate estimation of the RRs, we used a binomial regression model with log link when analysing each of the following outcomes: proportion of planned preventive consultations, additional preventive consultations and performed spirometries, as well as the proportion of patients who had contact to the out-of-hours services, who were admitted with or without a lung-related diagnosis and who had contact to the emergency department. A negative binomial regression model allowing for the heterogeneity between subjects [49] was used to analyse the counts of the following outcomes: conventional consultations, contacts to the out-of-hours services, use of bed days, contacts to the outpatient services with or without a lung-related diagnosis, number of contacts to the emergency department, number of admissions with or without a lung-related diagnosis and number of readmissions. Confidence intervals (CIs) at 95\% were assessed by performing robust variance estimation to account for a cluster effect at the GP level and, consequently, also at the patient level. Adjustment was made for age and gender, although this had minimal influence on the estimates of interest.

We performed intention-to-treat analysis for the algorithm-identified population and for the $\mathrm{CD}$ population who had been identified by the algorithm and who had themselves confirmed their diagnosis.

To examine the effectiveness and efficiency of the active implementation model, we performed an additional sensibility analysis where the two non-participating practices were omitted from the analysis and practices actually taking part in the intervention were analysed as intervention practices; we called the sub-group with this distribution of patients the EI population.

Analyses were performed using STATA version 11.0. The trial was performed in accordance with the CONSORT statement extended for cluster-randomised controlled trials [50].

\section{Ethics}

The study was recommended by the Committee of Multipractice Studies in General Practice under the Danish College of General Practitioners and by the Organisation of General Practitioners in Denmark (MPU 172009). The study was approved by the Danish Data Protection Agency (J.nr. 2008-41-2855) and the Danish Health and Medicines Authority (J.nr. 7-604-04-2/71 /EHE). The RCT was indexed at http://www.clinicaltrials. gov/show/NCT01228708 (ID number: NCT01228708). The present project did not require approval under the Danish health research ethics committee system (the Committee Act).

\section{Results}

\section{Patients}

The patients identified by the algorithm and those patients who also confirmed their COPD diagnosis, i.e. the CD group, are characterised in Table 2. In the CD group, the intervention group counted 458 (33.4\%) patients, the control group 376 (27.4\%) patients and the external control group 538 (39.2\%) patients. The EI population comprised $406(29.6 \%)$ patients in the intervention group, $376(27.4 \%)$ patients in the control group and 538 (39.2\%) patients in the external control group (Figure 1).

\section{Primary outcome}

Tables 3 and 4 show the changes in each group and the differences in changes between the groups for the study population. Data from the sub-group analysis are not shown.

The number of patients who had a planned preventive consultation rose statistically significantly in the intervention practices compared with the control practices 
Table 2 Baseline data for patients as listed in the Danish Health Insurance Service Registry by 1 November 2008

\begin{tabular}{|c|c|c|c|c|}
\hline \multicolumn{5}{|c|}{ Patients identified by COPD algorithm } \\
\hline & Intervention & Control & Ext. control & Total \\
\hline $\mathrm{N}(\%)$ & $877(32.1)$ & $766(28.0)$ & $1,092(39.9)$ & $2,735(100)$ \\
\hline Men (\%) & $399(45.5)$ & $354(46.2)$ & $492(45.0)$ & $1,244(45.5)$ \\
\hline Female (\%) & $478(54.5)$ & $412(53.8)$ & $600(55.0)$ & $1,491(54.5)$ \\
\hline Mean age (min-max) & $63.9(35-97)$ & $63.3(35-96)$ & $63.3(35-101)$ & $63.5(35-101)$ \\
\hline \multicolumn{5}{|c|}{ CD Population } \\
\hline \multicolumn{5}{|c|}{ Patients identified by algorithm who confirmed that they had COPD } \\
\hline & Intervention & Control & Ext. control & Total \\
\hline n (\%) & $458(33.4)$ & $376(27.4)$ & $538(39.2)$ & $1,372(100)$ \\
\hline Proportion of $\mathrm{N}(\%)$ & 52.2 & 49.1 & 49.3 & 50.2 \\
\hline Mean age (min-max) & $222(48.5)$ & $179(47.6)$ & $264(49.1)$ & $665(48.5)$ \\
\hline Men (\%) & $236(51.5)$ & $197(52.4)$ & $274(50.9)$ & $707(51.5)$ \\
\hline Female (\%) & $67.6(36-91)$ & $66.3(35-91)$ & $66.7(36-94)$ & $66.9(35-94)$ \\
\hline
\end{tabular}

$(\mathrm{RR}=1.77, \mathrm{p}=0.001)$. Intervention patients doubled their additional preventive consultations $(R R=2.03, p=0.004)$ and more had a spirometry at least once a year $(\mathrm{RR}=1.36, \mathrm{p}=0.006)$.

Interestingly, the use of conventional consultations decreased among the patients in the intervention group, while an increase was seen in the control group; thus, there was a statistically significant difference in use of conventional consultations $(\mathrm{RR}=0.85, \mathrm{p}=0.005)$.

\section{Secondary outcome}

Patients from the control group made more contacts to the out-of-hours services at the end of the study period than in the beginning (IRR=1.22, $\mathrm{p}=0.032$ ). No difference in the change of contacts to out-of-hours services was observed between the intervention group and the control groups.

Fewer patients from the intervention group were admitted without a lung-related diagnosis than in the control group ( $R R=0.71, p=0.018)$; and fewer patients from the intervention group were readmitted than in the external control group (IRR=0.33, $\mathrm{p}=0.003)$. The use of hospital bed days did not change in the intervention group; whereas it rose in the control group (IRR $=1.35$, $\mathrm{p}=0.008$ )

Although patients from the external control group visited the outpatient services more at the end of the study period (IRR=1.41, $\mathrm{p}=0.002$ ), there was no difference in the change in visits to the outpatient services between the intervention group and either the control group or the external control group.

No difference was observed in the three groups' use of emergency department services before and after the intervention.

\section{Sensitivity analyses}

The results of the analysis in which the data from the two practices that did not participate in the intervention were removed were fairly similar to the findings reported above although there were two new findings: more patients in the intervention group than in the control group had an additional preventive consultation $(\mathrm{RR}=1.95, \mathrm{p}=0.049)$ and the number of acute admissions in the intervention group fell to less than half $(R R=0.43, p=0.002)$ (data not shown). The same was the case for the results for the population identified by the algorithm both for the intention-to-treat and the sensitivity analysis (data not shown). For the population identified by the algorithm, the intention-to-treat analysis showed the same number of readmissions in the intervention group after the active implementation, but the number of readmissions rose in both the control group and the external control group (IRR=1.41, $\mathrm{p}<0.001$; and $\operatorname{IRR}=1.66, \mathrm{p}=0.014)$.

\section{Discussion}

\section{Principal findings}

Our study showed an effect of the intervention on planned and additional preventive consultations, performed spirometries and admissions. Thus, the intervention changed the management of patients with COPD.

\section{Strength and limitations of the study}

This study draws strength from its randomised design, the high number of included GPs and patients, and the use of highly valid administrative data. The results have been analysed both for the population identified by the COPD algorithm and for the study population where patients had confirmed their diagnosis. It adds to the strength of the study that the study population's results were either reproduced in the sub-group analysis or even 
Table 3 Rates and rate ratios (RRs) for specific variables presented with $95 \%$ confidence intervals

\begin{tabular}{|c|c|c|c|c|c|c|c|}
\hline$N=1372$ & & $\begin{array}{l}\text { Intervention } \\
(\mathrm{N}=458)\end{array}$ & $\begin{array}{l}\text { Control } \\
(\mathrm{N}=376)\end{array}$ & $\begin{array}{l}\text { Ext. control } \\
(\mathrm{N}=538)\end{array}$ & $\begin{array}{l}\text { Intervention } \\
\text { vs. Control } \\
\text { RR }\end{array}$ & $\begin{array}{l}\text { Intervention } \\
\text { vs. Ext } \\
\text { control RR }\end{array}$ & $\begin{array}{c}\text { Control vs. } \\
\text { Ext control } \\
\text { RR }\end{array}$ \\
\hline Number of patients who had a planned preventive & $2008-09$ & $\mathbf{0 . 3 4} 0.27 ; 0.44$ & $\mathbf{0 . 2 4} 0.17 ; 0.33$ & $\mathbf{0 . 2 5} 0.14 ; 0.45$ & $1.430 .96 ; 2.13$ & $1.350 .72 ; 2.52$ & $0.950 .49 ; 1.81$ \\
\hline \multirow[t]{2}{*}{ consultation } & 2009-10 & $0.530 .42 ; 0.68$ & $\mathbf{0 . 2 1} 0.15 ; 0.30$ & $0.290 .17 ; 0.48$ & $\mathbf{2 . 5 2 ^ { 1 }} 1.62 ; 3.92$ & $\mathbf{1 . 8 4 ^ { 1 }} 1.05 ; 3.24$ & $\mathbf{0 . 7 3} 0.39 ; 1.36$ \\
\hline & RR & $\mathbf{1 . 5 5 ^ { \mathbf { 2 } }} 1.23 ; 1.96$ & $0.880 .69 ; 1.12$ & $\mathbf{1 . 1 4} 0.91 ; 1.42$ & $\mathbf{1 . 7 7 ^ { \mathbf { 2 } }} 1.26 ; 2.48$ & $1.360 .98 ; 1.88$ & $\mathbf{0 . 7 7} 0.55 ; 1.07$ \\
\hline Number of patients who had an additional & 2008-09 & $0.110 .05 ; 0.27$ & $0.060 .03 ; 0.14$ & $0.100 .06 ; 0.18$ & $1.860 .56 ; 6.17$ & $1.090 .39 ; 3.07$ & $\mathbf{0 . 5 9} 0.22 ; 1.55$ \\
\hline \multirow[t]{2}{*}{ preventive consultation } & 2009-10 & $0.230 .11 ; 0.48$ & $0.08 \quad 0.03 ; 0.21$ & $0.120 .07 ; 0.24$ & $3.000 .87 ; 10.35$ & $1.860 .70 ; 4.91$ & $\mathbf{0 . 6 2} 0.19 ; 2.03$ \\
\hline & RR & $\mathbf{2 . 0 3 ^ { 2 }} 1.26 ; 3.27$ & $1.260 .84 ; 1.89$ & $1.190 .84 ; 1.71$ & $1.610 .86 ; 3.01$ & $1.700 .94 ; 3.09$ & $1.050 .62 ; 1.81$ \\
\hline Number of patients who had a spirometry & 2008-09 & $0.330 .26 ; 0.41$ & $0.230 .16 ; 0.33$ & $0.220 .17 ; 0.28$ & $1.430 .92 ; 2.23$ & $\mathbf{1 . 4 8}^{\mathbf{1}} 1.05 ; 2.08$ & $1.030 .66 ; 1.63$ \\
\hline \multirow[t]{2}{*}{ performed at the GP practice } & 2009-10 & $0.450 .34 ; 0.58$ & $0.240 .16 ; 0.36$ & $0.220 .15 ; 0.34$ & $\mathbf{1 . 8 2} \mathbf{2}^{\mathbf{1}} 1.23 ; 2.94$ & 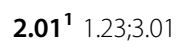 & $1.100 .62 ; 1.96$ \\
\hline & RR & $1.36^{1} 1.09 ; 1.70$ & $1.070 .85 ; 1.34$ & $1.000 .70 ; 1.44$ & $1.270 .93 ; 1.75$ & $1.360 .89 ; 2.08$ & $1.070 .70 ; 1.64$ \\
\hline Number of patients who were admitted to hospital & 2008-09 & $\mathbf{0 . 2 4} 0.20 ; 0.29$ & $\mathbf{0 . 2 1} 0.17 ; 0.26$ & $0.240 .21 ; 0.28$ & $1.160 .86 ; 1.55$ & $1.010 .80 ; 1.29$ & $\mathbf{0 . 8 8} 0.67 ; 1.15$ \\
\hline \multirow[t]{2}{*}{ without a lung-related diagnosis } & 2009-10 & $0.220 .18 ; 0.26$ & $\mathbf{0 . 2 6} 0.23 ; 0.30$ & $\mathbf{0 . 2 6} 0.21 ; 0.31$ & $\mathbf{0 . 8 2} 0.66 ; 1.02$ & $\mathbf{0 . 8 3} 0.64 ; 1.07$ & $1.010 .81 ; 1.26$ \\
\hline & $\mathbf{R R}$ & $\mathbf{0 . 8 8} 0.74 ; 1.05$ & $1.240 .99 ; 1.56$ & $1.08 \quad 0.92 ; 1.26$ & $\mathbf{0 . 7 1 ^ { \mathbf { 2 } }} 0.53 ; 0.94$ & $\mathbf{0 . 8 2} 0.65 ; 1.03$ & $1.150 .87 ; 1.52$ \\
\hline
\end{tabular}

${ }^{1}$ Statistical significance $\mathrm{p} \leq 0.05$.

No noteworthy difference was found for the proportion admitted with a lung-related diagnosis. Data not shown. 
Table 4 Counts and incidence rate ratios (IRRs) for specific variables presented with $95 \%$ confidence intervals

\begin{tabular}{|c|c|c|c|c|c|c|c|}
\hline$N=1372$ & & $\begin{array}{l}\text { Intervention } \\
(\mathrm{N}=458)\end{array}$ & $\begin{array}{l}\text { Control } \\
(\mathrm{N}=376)\end{array}$ & $\begin{array}{l}\text { Ext. control } \\
(\mathrm{N}=538)\end{array}$ & $\begin{array}{l}\text { Intervention vs. } \\
\text { Control IRR }\end{array}$ & $\begin{array}{l}\text { Intervention vs. } \\
\text { Ext control IRR }\end{array}$ & $\begin{array}{c}\text { Control vs. Ext } \\
\text { control IRR }\end{array}$ \\
\hline \multirow[t]{3}{*}{ Consultations with GP (daytime) } & 2008-09 & $7.756 .76-8.87$ & $7.576 .43-8.92$ & $6.756 .24-7.29$ & $1.020 .83-1.26$ & $1.150 .98-1.34$ & $1.120 .94-1.34$ \\
\hline & 2009-10 & $7.346 .60-8.17$ & $8.507 .12-10.14$ & $7.286 .73-7.88$ & $\mathbf{0 . 8 6} 0.71-1.06$ & $1.010 .88-1.15$ & $1.170 .96-1.41$ \\
\hline & IRR & $0.950 .88-1.02$ & $\mathbf{1 . 1 2 ^ { 2 }} 1.08-1.17$ & $1.08^{2} 1.02-1.44$ & $\mathbf{0 . 8 5 ^ { 2 }} 0.78-0.92$ & $\mathbf{0 . 8 8 ^ { 1 }} 0.80-0.96$ & $1.040 .97-1.12$ \\
\hline \multirow[t]{3}{*}{ Contacts to out-of-hours services } & 2008-09 & $\mathbf{0 . 6 8} 0.47-0.98$ & $\mathbf{0 . 6 0} 0.42-0.86$ & $\mathbf{0 . 6 1} 0.51-0.74$ & $1.120 .66-1.90$ & $1.100 .73-1.66$ & $\mathbf{0 . 9 9} 0.66-1.47$ \\
\hline & 2009-10 & $\mathbf{0 . 6 9} 0.47-1.01$ & $\mathbf{0 . 7 4} 0.56-0.98$ & $\mathbf{0 . 5 6} 0.46-0.68$ & $\mathbf{0 . 9 3} 0.60-1.45$ & $1.230 .83-1.83$ & $1.320 .94-1.85$ \\
\hline & IRR & $1.020 .85-1.22$ & $1.22^{1} 1.02-1.48$ & $0.920 .78-1.08$ & $0.830 .64-1.08$ & $1.120 .88-1.42$ & $\mathbf{1 . 3 4} \mathbf{1}^{\mathbf{1}} 1.05-1.71$ \\
\hline \multirow[t]{3}{*}{ Admissions with another diagnosis } & 2008-09 & $\mathbf{0 . 3 5} 0.27-0.45$ & $\mathbf{0 . 3 6} 0.28-0.46$ & $\mathbf{0 . 3 3} 0.28-0.38$ & $0.970 .68-1.38$ & $1.060 .79-1.43$ & $1.100 .82-1.46$ \\
\hline & 2009-10 & $0.330 .27-0.41$ & $\mathbf{0 . 4 7} 0.38-0.58$ & $0.450 .36-0.56$ & $\mathbf{0 . 7 0 ^ { 1 }} 0.52-0.94$ & $\mathbf{0 . 7 4} 0.55-1.01$ & $1.060 .78-1.43$ \\
\hline & IRR & $0.950 .69-1.32$ & $1.310 .91-1.88$ & $1.36^{1} 1.06-1.74$ & $\mathbf{0 . 7 3} 0.44-1.18$ & $\mathbf{0 . 7 0} 0.47-1.05$ & $0.960 .62-1.49$ \\
\hline \multirow[t]{3}{*}{ Bed days } & 2008-09 & $1.561 .09-2.22$ & $2.071 .55-2.63$ & $1.481 .11-1.98$ & $0.770 .49-1.21$ & $1.050 .67-1.63$ & $1.360 .90-2.06$ \\
\hline & 2009-10 & $1.611 .33-1.96$ & $1.701 .26-2.29$ & $2.011 .59-2.56$ & $\mathbf{0 . 9 5} 0.66-1.36$ & $\mathbf{0 . 8 0} 0.60-1.07$ & $\mathbf{0 . 8 4} 0.58-1.23$ \\
\hline & IRR & $1.040 .69-1.56$ & $0.840 .64-1.11$ & $1.36^{1} 1.09-1.70$ & $1.23 \quad 0.75-2.02$ & $0.760 .48-1.21$ & $\mathbf{0 . 6 2 ^ { 1 }} 0.43-0.89$ \\
\hline \multirow[t]{3}{*}{ Readmissions^ } & 2008-09 & $\mathbf{0 . 0 7} 0.05-0.12$ & $0.130 .10-0.17$ & $0.050 .04-0.08$ & $0.56^{1} 0.33-0.97$ & $1.380 .78-2.47$ & $\mathbf{2 . 4 5} \mathbf{5}^{\mathbf{2}} 1.53-3.94$ \\
\hline & 2009-10 & $\mathbf{0 . 0 7} 0.05-0.09$ & $\mathbf{0 . 1 2} 0.06-0.21$ & $\mathbf{0 . 1 4} 0.11-0.19$ & $\mathbf{0 . 5 9} 0.30-1.15$ & $\mathbf{0 . 4 8 ^ { \mathbf { 1 } }} 0.32-0.72$ & $0.820 .42-1.60$ \\
\hline & IRR & $0.950 .55-1.63$ & $\mathbf{0 . 9 0} 0.50-1.64$ & $\mathbf{2 . 7 1 ^ { 2 }} 1.90-3.86$ & $1.050 .46-2.38$ & $\mathbf{0 . 3 5 ^ { 2 }} 0.18-0.66$ & $0.33^{2} 0.16-0.68$ \\
\hline Contacts to outpatient services with any & 2008-09 & $3.072 .70-3.48$ & $3.382 .83-4.03$ & $3.032 .59-3.54$ & $\mathbf{0 . 9 1} 0.73-1.32$ & $1.010 .84-1.22$ & $1.120 .88-1.42$ \\
\hline \multirow[t]{2}{*}{ diagnosis } & 2009-10 & $2.912 .55-3.34$ & $3.683 .30-4.11$ & $3.652 .96-4.49$ & $\mathbf{0 . 7 9 ^ { 2 }} 0.67-0.94$ & $\mathbf{0 . 8 0} 0.63-1.01$ & $1.010 .80-1.27$ \\
\hline & IRR & $0.950 .81-1.11$ & $1.090 .95-1.25$ & $\mathbf{1 . 2 0 ^ { 2 }} 1.22-1.29$ & $\mathbf{0 . 8 7} 0.71-1.07$ & $\mathbf{0 . 7 8 ^ { 1 }} 0.66-0.94$ & $0.900 .78-1.04$ \\
\hline Contacts to outpatient services with & 2008-09 & $\mathbf{0 . 1 6} 0.11-0.24$ & $\mathbf{0 . 2 8} 0.19-0.40$ & $\mathbf{0 . 1 9} 0.12: 0.30$ & $\mathbf{0 . 5 9 ^ { 1 }} 0.35-0.99$ & $\mathbf{0 . 8 6} 0.48-1.57$ & $1.470 .83-2.62$ \\
\hline \multirow[t]{2}{*}{ a lung-related diagnosis } & 2009-10 & $0.220 .13: 0.36$ & $\mathbf{0 . 2 8} 0.17-0.46$ & $\mathbf{0 . 2 6} 0.19-0.38$ & $\mathbf{0 . 7 8} 0.67-0.94$ & $\mathbf{0 . 8 3} 0.45-1.54$ & $1.070 .59-1.92$ \\
\hline & IRR & $1.350 .76-2.40$ & $1.020 .67-1.54$ & $1.41^{2} 1.13-1.74$ & $1.330 .65-2.70$ & $\mathbf{0 . 9 5} 0.51-1.81$ & $0.720 .46-1.15$ \\
\hline
\end{tabular}

$\wedge \mathrm{A}$ readmission was defined as an acute admission within 30 days of the last admission.

${ }^{1}$ Statistical significance $p \leq 0.05$.

No noteworthy difference was found for the admissions with a lung-related diagnosis. Data not shown. 
enhanced. A further strength springs from the fact that a strong trend towards the same results was identified in the analysis of the population identified by the algorithm alone.

The two practices with four GPs who declined to participate in the intervention were excluded in a subgroup analysis because we wanted to examine the effectiveness of the active implementation model. These two practices received none of the components of the active implementation. This could give rise to selection bias. However, the sub-group analysis showed an overall pattern very close to that of the intention-to-treat analysis, which assured us that this bias is not decisive.

In order to accommodate analyse changes over time we chose to exclude those patients who died during the trial. In case of large differences in mortality between groups, this could affect the results of the comparison of health care use in either direction. However, the nature of the intervention and the nature of the relatively slowly evolving disease convinced us that any influence of the intervention on the endpoint "death" would be negligible in a short-term perspective. This assumption was confirmed by the present data.

We did consider if research protection could be an issue for patients in the randomised groups. One could think that patients might tire of being contacted. Both the intervention group and the control group were exposed to the baseline and the follow-up questionnaire, but only intervention patients received a flyer with the questionnaire; this would hardly trigger an action to seek research protection. The present data show that the issue of research protection played only a negligible role for participation.

The use of a complex intervention [35] building on specific aspects of the CCM $[3,4]$ represented a special challenge. For example, we were unable to assess the effectiveness of the individual components of the intervention. The implementation was offered as a package and was evaluated as such even though each individual GP practice may have selected only particular elements from the full catalogue. This may have introduced variation as to which elements actually brought change. However, in these respects, the present implementation processes were in no way different from similar implementation processes in the healthcare system.

Despite our efforts to identify as many of the patients with known COPD as possible, our study is underpowered. We were only able to identify those patients who had been in contact with the healthcare system and for whom lung-related complaints had resulted in an action on the part of the healthcare system. When a method to detect COPD in the earlier stages has been developed, patients with milder degrees of COPD can be included in the analyses. This will allow us to conduct a study of a larger scale; alternatively, the study can be extended to more municipalities participating in the randomised study.

An independent person randomised GP practices to the intervention or the control group. However, after the randomisation, we could not conceal the allocation to the researchers who performed the analysis because this group of researchers was also the one which conducted the intervention with the intervention practices. This could be considered a flaw in the study design.

One weakness of the present intervention, which is shared by most health services research, is that some intervention elements (e.g. recruitment of patients for the courses) were available for patients from the entire Ringkoebing-Skjern Municipality and not exclusively for patients from the intervention practices. This may lead to a serious underestimation of the effect and could imply that we have found the least possible difference between the study groups.

The understanding of the intervention could have been enhanced by including a process evaluation component into the study. For example, we could have interviewed the patients and/or the health professionals.

The added external control group further strengthened the study because it allowed us to check the spillover effect within the CME groups and in the common health services for all COPD patients.

\section{Comparison with other studies}

Other studies have shown similar effects of targeted, planned and evidence-based interventions for patients with chronic conditions [51-53] even when the impact was measured after ten years [54], whereas others have found no effects [55]. One meta-analysis suggests that comparing implementation strategies may establish sound evidence for the effectiveness of the successful implementation of programmes [56].

In a systematic review of the use of the CCM for COPD prevention and management, Adams et al. drew the conclusion that patients with COPD who received two or more components of the CCM had fewer unscheduled/emergency-room visits, fewer hospitalisations and showed a trend towards reduced healthcare costs compared with the control groups [57]. We made a similar observation, even if the effect on the use of the emergency department visits was minimal and we used healthcare utilization as a proxy for healthcare costs.

The intervention with the components that we selected is directly transferrable and applicable in future multifaceted interventions for chronic conditions in general practice.

Our finding of less use of hospital services after active implementation of a disease management programme is highly relevant as other studies have shown an increase 
of 2.3 in hospital admission rates for COPD patients compared with patients without COPD [58].

\section{Unanswered questions and future research}

The study period was two years with one year before the intervention start and one year after. The effect may have been different if the study had covered a longer period of time.

We measured healthcare utilization as a proxy for economic evaluation. A detailed and more comprehensive analysis, including the costs of the implementation, is needed. Consideration of the economic aspects of the active implementation of optimised healthcare for patients with COPD would also be of future interest.

The study would benefit from a deeper look into the black box of the intervention. An added process evaluation component could provide such insight as would also a future study with interviews with patients and/or with healthcare professionals. Another future study could include the component in a mixed methods study.

Multimorbidity is often the norm in general practice. A strategy like the implementation model used in the present study may be an effective tool to coordinate healthcare services for patients with multimorbidity. A future study including patients with multimorbidity would be of much interest to clinicians and politicians.

Our findings in this randomised study and the success of similar programmes for other chronic diseases highlight the potential and the need for larger long-term studies. Such studies should explore activities and implementation strategies that could easily be adopted in GP practices and should comprise multiple components of the CCM with a view to preventing complications and improving outcomes for patients with COPD.

\section{Conclusions}

The multifaceted implementation of a disease management programme for COPD made general practice follow the programme and proactively perform follow-up consultations and spirometries. This resulted in a decline in the number of GP consultations and a tendency towards decreased use of hospital services. Use of out-of-hours services remained the same although patients from the control group increased their use of these services. No effect on the use of the emergency department was found. The implementation model can be applied in future multifaceted interventions targeting patients with chronic disease.

\section{Additional file}

Additional file 1: The PaTPlot depicting the timeline and the contents of the active implementation model. Squares illustrate fixed object, e.g. printed materials like questionnaires. Circles illustrate an activity was involved in the component, e.g. Continuing Medical Education meetings.

\section{Abbreviations}

AT: As treated; CCM: Chronic Care Model; CD: Confirmed Diagnosis;

$\mathrm{Cl}$ : Confidence Interval; COPD: Chronic Obstructive Pulmonary Disease; GP: General Practitioner.

\section{Competing interests}

The authors declare that they have no competing interests.

\section{Authors' contributions}

FO, PV and MS designed the study. MS, PV, FO and MBC participated in the study and in drafting the manuscript. MFG assisted with statistical analysis and in drafting the manuscript. All authors have read and approved the final manuscript.

\section{Acknowledgements}

The study was carried out at the Research Unit for General Practice in Aarhus and further funded by the Ringkoebing-Skjern Municipality, the Central Denmark Region and the Medical Research Fund at Aarhus University, Denmark.

We are grateful to patients, GPs and Sundhedscenter Vest of the Ringkoebing-Skjern Municipality for participating in the study. We thank Dr. Robert Stockley, University of Birmingham, United Kingdom, for permission to use his sputum chart and Dr. Erik Juul Jensen, Hospitalsenheden Vest, the Central Denmark Region, for providing support during the intervention. We wish to thank GP Lars Foged, the town of Skjern, and Director Ulla Svendsen, Sundhedscenter Vest of the Ringkoebing-Skjern Municipality, and Chief Consultant Steen Vestergaard-Madsen, the Central Denmark Region for supporting the idea.

Received: 21 February 2013 Accepted: 16 September 2013

Published: 3 October 2013

\section{References}

1. Barnett K, Mercer SW, Norbury M, Watt G, Wyke S, Guthrie B: Epidemiology of multimorbidity and implications for health care, research, and medical education: a cross-sectional study. Lancet 2012, 380:7-9.

2. Danske regioner: Fremtidens Almen Praksis; 2010. http://www.regioner.dk/ Publikationer/Sundhed+og+sygehuse/ /media/migration\%20folder/upload/ filer/sundhed/praksis\%20magasin\%20web_med\%20ny\%20forside.pdf.ashx. (The Future's General Practice) [In Danish].

3. Bodenheimer T, Wagner EH, Grumbach K: Improving primary care for patients with chronic illness. JAMA 2002, 288:1775-9.

4. Bodenheimer T, Wagner EH, Grumbach K: Improving primary care for patients with chronic illness: the chronic care model, Part 2. JAMA 2002, 288:1909-14.

5. Wagner EH, Austin BT, Von KM: Improving outcomes in chronic illness. Manag Care Q 1996, 4:12-25.

6. Feachem RG, Sekhri NK, White KL: Getting more for their dollar: a comparison of the NHS with California's Kaiser Permanente. BMJ 2002, 324:135-41.

7. Vondeling $\mathrm{H}$ : Economic evaluation of integrated care: an introduction. Int J Integr Care 2004, 4:e20.

8. Wennberg J, Gittelsohn A: Variations in medical care among small areas. Sci Am 1982, 246:100-11.

9. World Health Organization: WHO Disease and injury country estimates; 2009 http://www.who.int/healthinfo/global_burden_disease/estimates_country/ en/index.html.

10. Christensen K, Bjørk C, Vinther-Larsen M, Løkkegaard E, Grønbæk M: Otte folkesygdomme - Forekomst og udvikling. (Eight prevalent diseases - Incidence and progression), [In Danish]. København: Statens Institut for Folkesundhed; 2005.

11. Pauwels RA, Buist AS, Ma P, Jenkins CR, Hurd SS: Global strategy for the diagnosis, management, and prevention of chronic obstructive pulmonary disease: National Heart, Lung, and Blood Institute and World Health Organization Global Initiative for Chronic Obstructive Lung Disease (GOLD): executive summary. Respir Care 2001, 46(8):798-825.

12. Løkke A, Lange P, Scharling H, Fabricius P, Vestbo J: Developing COPD: a 25 year follow up study of the general population. Thorax 2006, 61:935-9.

13. Hansen JG, Pedersen L, Overvad K, Omland O, Jensen HK, Sorensen HT: Prevalence of chronic obstructive pulmonary disease-secondary publication. Ugeskr Laeger 2009, 171:2986-8.

14. Midtjylland R: Forløbsprogram for Kronisk Obstruktiv Lungesygdom - Kliniske retningslinjer, tjeklister og vejledninger. Viborg: Region Midtjylland; 2008. (Disease 
management programme for COPD - Clinical guidelines, checklists and guidelines), [In Danish].

15. Grol $R$, Wensing M: What drives change? Barriers to and incentives for achieving evidence-based practice. Med J Aust 2004, 180(6 Suppl):S57-S60.

16. Grol R, Grimshaw J: From best evidence to best practice: effective implementation of change in patients' care. Lancet 2003, 362:1225-30.

17. Lugtenberg M, Burgers JS, Westert GP: Effects of evidence-based clinica practice guidelines on quality of care: a systematic review. Qual Saf Health Care 2009, 18:385-92.

18. Greenhalgh T, Robert G, Bate P, Macfarlane F, Kyriakidou O: Diffusion of Innovations in Health Service Organisations. A systematic literature review. Oxford: Blackwell Publishing; 2005.

19. Grol R: Changing physicians' competence and performance: finding the balance between the individual and the organization. $J$ Contin Educ Health Prof 2002, 22:244-51.

20. Nolte $E$, McKee M: Measuring the health of nations: analysis of mortality amenable to health care. BMJ 2003, 327:1129.

21. Lorig KR, Ritter P, Stewart AL, Sobel DS, Brown BW Jr, Bandura A, Gonzalez VM, Laurent DD, Holman HR: Chronic disease self-management program: 2-year health status and health care utilization outcomes. Med Care 2001, 39:1217-23.

22. Gadoury MA, Schwartzman $K$, Rouleau M, Maltais F, Julien M, Beaupre A Renzi P, Begin R, Nault D, Bourbeau J: Self-management reduces both short- and long-term hospitalisation in COPD. Eur Respir J 2005, 26:853-7.

23. Hendriks JL, Nieuwlaat R, Vrijhoef HJ, De WR, Crijns HJ, Tieleman RG: Improving guideline adherence in the treatment of atrial fibrillation by implementing an integrated chronic care program. Neth Heart J 2010, 18:471-7.

24. Sidorov J, Shull R, Tomcavage J, Girolami S, Lawton N, Harris R: Does diabetes disease management save money and improve outcomes? A report of simultaneous short-term savings and quality improvement associated with a health maintenance organization-sponsored disease management program among patients fulfilling health employer data and information set criteria. Diabetes Care 2002, 25:684-9.

25. Condelius A, Hallberg IR, Jakobsson U: Hospital and outpatient clinic utilization among older people in the 3-5 years following the initiation of continuing care: a longitudinal cohort study. BMC Health Serv Res 2011, 11:136.

26. Rabe KF: Guidelines for chronic obstructive pulmonary disease treatment and issues of implementation. Proc Am Thorac Soc 2006, 3:641-4.

27. Sin DD, Bell NR, Svenson LW, Man SF: The impact of follow-up physician visits on emergency readmissions for patients with asthma and chronic obstructive pulmonary disease: a population-based study. Am J Med 2002, 112:120-5.

28. Wagner EH, Austin BT, Davis C, Hindmarsh M, Schaefer J, Bonomi A: Improving chronic illness care: translating evidence into action. Health Aff (Millwood) 2001, 20:64-78.

29. Fletcher RH, Fletcher SW, Wagner EH: Clinical Epidemiology. The Essentials. 3rd edition. Baltimore: Williams \& Wilkins; 1996.

30. Verstappen WH, Van der WT, G TR, Grimshaw J, Winkens R, Grol RP: Block design allowed for control of the Hawthorne effect in a randomized controlled trial of test ordering. J Clin Epidemiol 2004, 57:1119-23.

31. Smidth M, Sokolowski I, Kærsvang $L$, Vedsted P: Developing an algorithm to identify people with Chronic Obstructive Pulmonary Disease (COPD) using administrative data. BMC Med Inform Decis Mak 2012, 12:38.

32. Pedersen CB: The Danish Civil Registration System. Scand J Public Health 2011, 39(7 suppl):22-5

33. Sahl Andersen J, De Fine ON, Krasnik A: The Danish National Health Service Register. Scand J Public Health 2011, 39(7 suppl):34-7.

34. Flarup L, Moth G, Christensen MB, Vedsted P, Olesen F: Den danske læegevagt i internationalt perspektiv - en sammenlignende undersøgelse af lægevagt i Danmark, England, Holland, Norge og Sverige. 1st edition. Aarhus: Forskningsenheden for Almen Praksis, Aarhus Universitet; 2010. (The Danish out-of-hours service in an international perspective - a comparative study of out-of-hours senvices in Denmark, United Kingdom, The Netherlands, Norway and Sweden), [In Danish].

35. Smidth M, Christensen MB, Olesen F, Vedsted P: Developing an active implementation model for a chronic disease management program. Int J Integr Care. in press.

36. Wagner EH: Chronic disease management: what will it take to improve care for chronic illness? Eff Clin Pract 1998, 1:2-4.
37. Stross JK: The Educationally Influential Physician. J Contin Educ Health Prof 1996, 16:167-72.

38. Improving chronic illness care. http://www.improvingchroniccare.org/index. php?p=About_US\&s=6. 2-5-2012.

39. Langley GJ, Nolan KM, Nolan TW, Clifford LN, Provost LP: The Improvement Guide: A Practical Approach to Enhancing Organizational Performance. San Francisco: Jossey-Bass; 1996.

40. Wensing $M$, van der Weijden $T$, Grol R: Implementing Guidelines and innovations in general practice: which interventions are effective? Brit J Gen Pract 1998, 48:991-997.

41. Stockley RA, O'Brien C, Pye A, Hill SL: Relationship of sputum color to nature and outpatient management of acute exacerbations of COPD. Chest 2000, 117:1638-45.

42. Gompertz S, O'Brien C, Bayley DL, Hill SL, Stockley RA: Changes in bronchial inflammation during acute exacerbations of chronic bronchitis. Eur Respir J 2001, 117:1112-9.

43. Bestall JC, Paul EA, Garrod R, Garnham R, Jones PW, Wedzicha JA: Usefulness of the Medical Research Council (MRC) dyspnoea scale as a measure of disability in patients with chronic obstructive pulmonary disease. Thorax 1999, 54:581-6.

44. Olsen LR, Jensen DV, Noerholm V, Martiny K, Bech P: The internal and external validity of the Major Depression Inventory in measuring severity of depressive states. Psychol Med 2003, 33:351-6.

45. Sorensen J, Davidsen M, Gudex C, Pedersen KM, Bronnum-Hansen H: Danish EQ-5D population norms. Scand J Public Health 2009, 37:467-74

46. Glasgow RE, Wagner EH, Schaefer J, Mahoney LD, Reid RJ, Greene SM: Development and validation of the Patient Assessment of Chronic Illness Care (PACIC). Med Care 2005, 43:436-44.

47. Vedsted P, Sokolowski I, Heje HN: Data quality and confirmatory factor analysis of the Danish EUROPEP questionnaire on patient evaluation of general practice. Scand J Prim Health Care 2008, 26:174-80.

48. Smidth M, Olesen F, Fenger-Grøn M, Vedsted P: Patient-experienced effect of an active implementation of a disease management programme for COPD - a randomised trial. BMC Fam Pract 2013, 14:147.

49. Thomsen $\mathrm{J}$, Parner ET: Methods for analysing recurrent events in health care data. Examples from admissions in Ebeltoft Health Promotion Project. Fam Pract 2006, 23:407-13.

50. Campbell MK, Elbourne DR, Altman DG: CONSORT statement: extension to cluster randomised trials. BMJ 2004, 328:702-8.

51. Mason J, Freemantle N, Nazareth I, Eccles M, Haines A, Drummond M: When is it cost-effective to change the behavior of health professionals? JAMA 2001, 286:2988-92

52. Tsai AC, Morton SC, Mangione CM, Keeler EB: A meta-analysis of interventions to improve care for chronic illnesses. Am J Manag Care 2005, 11:478-88.

53. McLean S, Chandler D, Nurmatov U, Liu J, Pagliari C, Car J, Sheikh A: Telehealthcare for asthma: a Cochrane review. CMAJ 2011, 183:E733-E742.

54. Ogden T, Bjornebekk G, Kjobli J, Patras J, Christiansen T, Taraldsen K, Tollefsen N: Measurement of implementation components ten years after a nationwide introduction of empirically supported programs - a pilot study. Implement SCi 2012, 31(7):49.

55. Brand C, Landgren F, Hutchinson A, Jones C, Macgregor L, Campbell D: Clinical practice guidelines: barriers to durability after effective early implementation. Intern Med J 2005, 35:162-9.

56. Francke AL, Smit MC, De Veer AJ, Mistiaen P: Factors influencing the implementation of clinical guidelines for health care professionals: a systematic meta-review. BMC Med Inform Decis Mak 2008, 8:38.

57. Adams SG, Smith PK, Allan PF, Anzueto A, Pugh JA, Cornell JE: Systematic review of the chronic care model in chronic obstructive pulmonary disease prevention and management. Arch Intern Med 2007, 167:551-61.

58. Mapel DW, Hurley JS, Frost FJ, Petersen HV, Picchi MA, Coultas DB: Health care utilization in chronic obstructive pulmonary disease. A case-control study in a health maintenance organization. Arch Intern Med 2000, 160:2653-8

doi:10.1186/1472-6963-13-385

Cite this article as: Smidth et al:: The effect of an active implementation of a disease management programme for chronic obstructive pulmonary disease on healthcare utilization - a cluster-randomised controlled trial. BMC Health Services Research 2013 13:385. 